\title{
Relações de trabalho e a saúde do trabalhador durante e após a pandemia de COVID-19
}

\author{
Labor relations and workers' health during and after the \\ COVID-19 pandemic
}

\author{
Relaciones laborales y salud de los trabajadores durante y \\ después de la pandemia de COVID-19
}

\begin{abstract}
OS IMPACTOS DA PANDEMIA PARA O TRABALHADOR E SUAS RELAÇÕES COM O TRABALHO. Moares MM, organizadora. Porto Alegre: Artmed; 2020. 77 p. (Coleção O Trabalho e as Medidas de Contenção da COVID-19: Contribuições da Psicologia Organizacional e do Trabalho, 2). ISBN: 978-88-7223-315-3.
\end{abstract}

doi: 10.1590/0102-311X00018321

A pandemia de COVID-19 suscitou ações de prevenção que impactaram fortemente a vida, a saúde e o trabalho. Entre elas o distanciamento físico, o fechamento de setores da economia, a adoção do trabalho remoto e as medidas de higiene pessoal. Além das consequências biomédicas, a pandemia trouxe consigo desemprego, precarização das condições e vínculos de trabalho, aumento da jornada sem aumento dos rendimentos, custos adicionais para os trabalhadores 1 e problemas psicoemocionais 2 .

Com o objetivo de colaborar com as reflexões e as ações necessárias nesse contexto desafiador, o livro Os Impactos da Pandemia para o Trabalhador e suas Relações com o Trabalho é parte da coletânea organizada pela Associação Brasileira de Psicologia Organizacional e do Trabalho, e aborda a temática com base em olhares e experiências de 19 pesquisadores da área.

A primeira discussão diz respeito à fragilização dos vínculos que se estabelecem nos relacionamentos com as pessoas e as organizações (comprometimento, entrincheiramento, consentimento e enraizamento). A tênue fronteira entre o trabalho e a vida, condição aflorada pelo trabalho remoto, impacta nos níveis e formas de manifestação dos vínculos, repercutindo na saúde mental dos indivíduos. As mudanças nos vínculos podem ser mais ou menos traumáticas dependendo de determinantes sociais como a cor da pele, o gênero e a classe social dos trabalhadores. Nesse contexto, sentimentos como medo, culpa e frustração afetam os trabalhadores e os vínculos que podem ser interrompidos ou exacerbados.

"Arranjos alternativos de trabalho diante da COVID-19" é outro tema relevante abordado no livro. Contempla trabalhadores autônomos e informais em uma multiplicidade de configurações do trabalho (trabalho contingencial, crowdsourcing, pejotização, uberização), que se caracterizam pela individualização, fragilização das relações contratuais, flexibilização do tempo e deslocalização do trabalho. Para esses trabalhadores a pandemia gerou diminuição da demanda de trabalho e de rendimentos, ampliando suas vulnerabilidades, reavivando debates sobre renda mínima e políticas de apoio social; a transferência de custos de treinamento, desenvolvimento, equipamentos, insumos e manutenção para os trabalhadores; e a exposição ao risco de contaminação, agravado pelas barreiras de acesso à seguridade social.

Nesse sentido, a pandemia amplificou a precarização do trabalho e abriu espaço para novos estressores. Ao discutir "saúde mental e quali- 
dade de vida no trabalho", os autores destacam grupos profissionais que vivenciam torções deflagradas pela pandemia, como os professores, forçados a se moverem da atividade presencial clássica à educação a distância. Enfrentar as crises que transcendem a dimensão sanitária e repercutem na dimensão do trabalho envolve considerar as experiências individuais, mas também a dinâmica do coletivo em relação a estas vivências. Assim, são lembrados os "médicos", "professores", "coveiros" e "policiais”, mas indubitavelmente os trabalhadores de estabelecimentos farmacêuticos e alimentícios (supermercados e padarias) que, considerados serviços essenciais, vivenciam crises das mais diversas ordens. $\mathrm{O}$ registro de casos de COVID-19 tem sido maior entre os trabalhadores do comércio, empregadas domésticas e trabalhadores da indústria, como motoristas de caminhões de transporte de carga e pedreiros 3 .

O tema da informalidade, forte característica do trabalho no Brasil, foi abordado no livro com pouco destaque para o contexto pandêmico. Considerando os determinantes do trabalho informal (desemprego, falta de políticas de amparo aos trabalhadores e precarização do trabalho), os autores discutem as funções e discursos vigentes sobre a uberização do trabalho e o empreendedorismo, usado como "saída privilegiada ao desemprego". Discutem ainda a diversidade de significações e a centralidade do trabalho na vida; a liberdade e o acesso imediato à renda; e a convivência entre competição e cooperação entre trabalhadores informais.

O contexto pandêmico gerou "novas demandas de aprendizagem" aos trabalhadores. A rápida adaptação ao trabalho remoto de caráter compulsório não foi acompanhada ou precedida de preparação material ou psicológica. Trabalhadores e gestores foram impelidos a adquirir habilidades afetivas para a comunicação mediada por tecnologias, assertividade para buscar ajuda e suporte social de colegas e superiores, aprender a regular os tempos de trabalho e descanso, equilibrar as atividades do trabalho com as domésticas e regular os diversos estados afetivos que o isolamento exacerbou.

A criatividade e a proatividade são apontadas como novas soluções para o trabalho em resposta à pandemia. A criatividade pode auxiliar no enfrentamento do novo, na adaptação ao ritmo acelerado das mudanças. A proatividade envolve uma atitude voltada para o futuro que extrapola a realização da atividade atribuída. Ambas permitem que o trabalhador identifique oportunidades, aja sobre elas e desenvolva novos métodos de trabalho aprimorando o seu desempenho.

Do ponto de vista organizacional, fomentar e estimular a criatividade dos trabalhadores permite às empresas uma melhor adaptação ao contexto de crise, e aos trabalhadores a sensação de pertencimento e capacidade de contribuir efetivamente. Para promover a criatividade, apontam-se fatores individuais (habilidades, motivações, personalidade); organizacionais (cultura e clima organizacional); sociais ligados ao trabalho (relação com líderes e pares); e relacionados à autonomia e demais características do trabalho.

As implicações da pandemia para as carreiras dos trabalhadores são destacadas com base na necessidade de compreender os efeitos das diferenças sociais e consequentes injustiças no desenvolvimento das carreiras em um contexto pós-pandemia, que pode variar de acordo com a modalidade contratual do trabalhador (formal $\mathrm{x}$ informal), gênero, etnia e setor produtivo.

Um dos pontos fortes do livro é a abordagem de determinantes sociais que implicam a maior vulnerabilidade para algumas categorias profissionais, particularmente para trabalhadores com vínculos e relações instáveis de trabalho. Assim como afirmam Santos et al. 3, a pandemia de COVID-19 descortinou uma conjuntura de perdas relevantes de direitos trabalhistas e previdenciários, que somadas às desigualdades sociais e às iniquidades em saúde expõem os trabalhadores a riscos pessoais e coletivos.

Como perspectivas futuras, o livro alerta que a evolução dos modelos de trabalho seguirá a evolução e a transformação digital, que certamente vai propiciar contextos de trabalho globalizados, pois a mobilidade será um requisito dispensável. Espera-se ainda um aumento de vínculos alternativos de trabalho, precarização e informalidade, com a permanência do modelo exploratório mediado pelos aplicativos, relação que mascara a responsabilidade das empresas e amplia as desigualdades pela ausência de garantias 2 .

Para o contexto do trabalho remoto e teletrabalho, apontam a necessidade de: (1) prezar pela 
participação e protagonismo dos trabalhadores na busca por soluções inovadoras, possibilidades de regulação/gestão e treinamento; (2) realizar diagnóstico organizacional para fundamentar planejamento, operacionalização, avaliação e replanejamento da promoção da saúde mental e física dos trabalhadores; (3) adequar a avaliação de desempenho e controle dos resultados às condições de produção (trabalho remoto e teletrabalho) para oferecer suporte organizacional e reduzir os riscos; (4) implementar programas de qualidade de vida no trabalho customizado, envolvendo todos os atores e com responsabilidade institucional; e (5) promover a aprendizagem e o desenvolvimento de habilidades (sociais, afetivas, gerenciais e instrumentais).

Finalizam o livro apontando que em contextos de emergência mundial como uma pandemia, é fundamental estimular a criatividade no ambiente de trabalho; propiciar um ambiente de aprendizado e autonomia dos trabalhadores; promover o diálogo, feedbacks e encorajamento, usando recompensas e metas realistas no contexto remoto.

Recomenda-se a leitura a gestores de recursos humanos, psicólogos e médicos do trabalho, além de gestores públicos e pesquisadores da área da Saúde Coletiva.

Graziella Lage Oliveira 1

Adalgisa Peixoto Ribeiro 1

1 Universidade Federal de Minas Gerais, Belo Horizonte,

Brasil.

grazilage.oliveira@gmail.com

\section{Colaboradores}

Ambas as autoras contribuíram com a escrita e revisão do texto.

\section{Informações adicionais}

ORCID: Graziella Lage Oliveira (0000-0002-33873583); Adalgisa Peixoto Ribeiro (0000-0001-94158068).

1. Abilio LC, Almeida PF, Amorim H, Cardoso ACM, Fonseca VP, Kalil RB, et al. Condições de trabalho de entregadores via plataforma digital durante a COVID-19. Revista Jurídica Trabalho e Desenvolvimento Humano 2020; 3:1-21.

2. Souza DO. As dimensões da precarização do trabalho em face da pandemia de Covid-19. Trab Educ Saúde 2021; 19:e00311143.

3. Santos KOB, Fernandes RCP, Almeida MMC, Miranda SS, Mise YF, Lima MAG. Trabalho, saúde e vulnerabilidade na pandemia de COVID-19. Cad Saúde Pública 2020; 36:e00178320. 